\title{
Lectura crítica de Falquet, Jules (2017). Pax neoliberalia: perspectivas feministas sobre (la reorganización de) la violencia contra las mujeres. Buenos Aires: Madreselva
}

\author{
Florencia Partenio \\ Universidad Nacional Arturo Jauretche, Argentina \\ florencia.partenio@gmail.com
}

Paxneoliberalia reúne cuatro ensayos situados en los casos de Turquía, México, Guatemala y El Salvador. Estos escritos se articulan en la continuidad de las reflexiones que Jules Falquet había iniciado en su libro Por las buenas o por las malas. Las mujeres en la globalización publicado en 2008, donde analizaba el papel de las instituciones internacionales -como la ONU y el Banco Mundial- y sus estrategias de apropiación de lenguajes y despolitización.

Estos ensayos fueron escritos en diferentes momentos, uno de ellos formó parte de su investigación para la tesis de doctorado a fines de los '90. Desde una edición cuidada por Madreselva Editorial, este libro va desanudando las tramas y dimensiones materiales de las violencias contra las mujeres. Dicha interpretación se enmarca en los análisis feministas materialistas francófonos de Nicole Claude Mathieu (1991) y Colette Guillaumin (1992), y de la antropóloga italiana Paola Tabet $(2004,2005)$.

La autora escribe desde una posición feminista antimilitarista -recuperando las reflexiones de Andrée Michel- para develarlas modalidades que adquiere la reorganización neoliberal de la violencia y las responsabilidades estatales de aquellos países que son base de la globalización. Esta posición se explaya en artículos donde analiza la dialéctica de la división sexual del trabajo en el complejo militaro-industrial (Falquet, 2014). Los ensayos reunidos en Paxneoliberalia, vuelven a evidenciar los vínculos entre los "hombres en armas" y las "mujeres de servicios" que son quienes garantizan la reproducción social en el mundo. Bajo este "estado paradójico e inestable”, en el que vivimos, la violencia contra las mujeres se vuelve una pieza clave para la acumulación capitalista.

En los cuatro ensayos se muestra cómo el avance neoliberal "descansa" en estos Estados yse evidencia en los cuantiosos beneficios económicos que provienen de la articulación de economías legales e ilegales, la producción en zonas fronterizas, el modelo de la "maquila" y la implementación de proyectos extractivistas. En este sentido, dialoga con los estudios de economía feminista sobre los flujos financieros lícitos e ilícitos, que sostienen la explotación de mujeres en el mundo y socavan la justicia tributaria y de género (Grondona, Bidegain Ponte y Rodríguez Enríquez, 2016).

Ahora bien, el trabajo de Falquet contribuye desde el feminismo materialista francófono a una serie de debates. Por un lado, entre aquellos estudios que mantienen fuertes cegueras de género cuando analizan las condiciones geopolíticas, las relaciones económicas norte-sur, los modelos de desarrollo asentados en mega-proyectos extractivistas y el impacto de las políticas generadas por los Tratados de "Libre" Comercio e Inversión (TLCI). La lectura de Falquet expone la militarización de los territorios y el desplazamiento de poblaciones por el avance de proyectos extractivistas, junto con las implicancias sobre la vida de mujeres, lesbianas y migrantes de lo que denomina la semi-privatización de la seguridad.

Por otro lado, Paxneoliberalia debate con los recientes estudios de masculinidades que caen -involuntaria o deliberadamente- en visiones masculinistas que terminan por individualizar o desresponsabilizar a los 
varones. En este caso, retoma el estudio en Turquía realizado en el 2014 por Pinar Selek donde se cuestionan las lecturas masculinistas que han mirado al servicio militar como "ritual de iniciación". Más bien se trata de un dispositivo que consolida la división social entre dos grupos radicalmente jerarquizados, cuando los varones jóvenes que se incorporan al servicio militar turco adquieren privilegios en una estructura jerárquica que excluye a las mujeres. Bajo este dispositivo, Falquet afirma que la violencia constituye un instrumento para inculcar la aceptación de la jerarquía. Ahora, esa violencia "era tan poco natural que era necesario aprender a ejercerla de cierta manera" (Falquet, 2017, p. 80).

En términos de analizar el mundo del trabajo y la explotación de la fuerza de trabajo, resulta interesante articular los estudios que evaluaron el lugar central del trabajo de las mujeres en el desarrollo de la globalización (Benería, 1991; Federici, 2013; Sanchís y Rodríguez Enríquez, 2011; Sassen, 2003) con el planteo de Falquet en torno a la (re)organización de la violencia. En particular, a través del "prisma" que representan los casos de feminicidios en Latinoamérica. En este sentido, cuestiona la noción de vulnerabilidad de las mujeres. A través de casos concretos, la autora va develando la economía política de los feminicidios, mostrando que se ataca a las personas más importantes para la reproducción social y la acumulación de capital: las trabajadoras. Traza una equivalencia cuando critica la noción de vulnerabilidad de las mujeres, porque sería como decir que el proletariado es vulnerable. Se trata de un término psicologizante y victimizante que no contribuye a diagramar la magnitud de la violencia ejercida. En este sentido, considera que las mujeres son, pero no vulnerables. En el caso de Ciudad Juárez, los asesinatos de mujeres entran a formar parte de una historia política y militar más amplia de México. Estas mujeres explotadas y apropiadas - pero no vulnerables- son figuras emblemáticas de la globalización neoliberal, porque crean beneficios y son combatidas para evitar que se organicen en sindicatos y resistan. Los feminicidios demuestran que esta mano de obra se vuelve visible precisamente a medida que está siendo especialmente atacada. En este caso, la autora va más allá de la hipótesis de Rita Laura Segato (2004).

Con la idea de desentrañar las "guerras de baja intensidad" desatadas contra las mujeres, Falquet vuelve sobre dos casos que conoce como son El Salvador y Guatemala.En este análisis, insiste en precisar las imbricaciones de las relaciones de sexo, raza y clase cuando se pregunta equé relación existe entre el ejercicio colectivo e institucionalizado de la violencia y el mantenimiento, consolidación y creación de grupos sociales, incluso de las diferentes clases (de sexo, de raza y sociales)?

En el primer caso, establece los puntos en común que tienen la violencia doméstica ejercida contra las mujeres en tiempos de paz en El Salvador y la tortura llamada política, tanto ensus métodos como en los efectos psicodinámicos producidos individualmente en las personas que las sufren. En el segundo caso, reconstruye la historia de Guatemala, como país que atravesó el primer golpe de Estado, organizado por la CIA y donde actualmentese desarrollan nuevas formas de violencia, bajo los proyectos extractivistas. La trama más potente de ambas experiencias se narra en esa lucha desde abajo, de grupo de mujeres, feministas y lésbicos, "que se han organizado colectivamente para reconstruirse y rechazar el estatus de víctimas donde el sistema intentaba instalarlas" (Falquet, 2017, p. 116) y porque confluye y se articula con luchas globales y locales, donde se involucran mujeres mestizas, indígenas y europeas. En ese camino de "sanación", de víctimas a "Actoras del Cambio", las compañeras guatemaltecas logran visibilizar las violencias sexuales durante el conflicto armado, conforman tribunales y realizan un trabajo de "memoria, curación y construcción", anclada en las culturas indígenas. Y aquí se plantea uno de los desafíos, como es el diálogo con los feminismos del sur, en particular, con la experiencia y valorización del feminismo comunitario.

Desde esa lucha y saberes, el libro concluye con un poema a Berta Cáceres. A modo de homenaje y mensaje de justicia y esperanza, la poeta Melissa Cardoza escribe esos versos a la feminista hondureña de la comunidad indígena Lenca y defensora de derechos humanos, integrante de COPINH. Por el camino de Berta, para celebrar nuestras luchas. 


\section{ReFERENCIAS}

Benería, L. (1991). La globalización de la economía y el trabajo de las mujeres, Economía y sociología del trabajo, 13-14, 23-35.

Falquet, J. (2011 [2008]). Por las buenas o por las malas. Las mujeres en la globalización. Bogotá: Universidad Nacional de Colombia.

Falquet, J. (2014). Hacia un análisis feminista y dialéctico de la globalización neoliberal: el peso del complejo militarindustrial sobre las 'mujeres globales'. Revista internacional de pensamiento politico, 9(2), 139-148.

Federici, S. (2013). Revolución en punto cero. Trabajo doméstico, reproducción y luchas feministas. Madrid: Traficantes de Sueños.

Guillaumin, C. (1992). Pratique Du pouvoiretidée de nature. Em C. Guillaumin, Sexe, raceet pratique dupouvoir. L'ide\#te de Nature (pp. 13-48). Paris: Côté-femmes.

Grondona, V., Bidegain Ponte, N. y Rodríguez Enríquez, C. (2016). Flujos financieros ilícitos que socavan la justicia de género. Nueva York: FES.

Mathieu, N.C. (1991). L'anatomiepolitique, catégorisations et idéologies du sexe. Paris: Côté Femme.

Sanchís, N. y Rodríguez Enríquez, C. (coords.) (2011). El papel de las migrantes paraguayas en la provisión de cuidados en la Argentina. Santo Domingo: ONU Mujeres.

Sassen, S. (2003). Contrageograías de la globalización. Género y ciudadanía en los circuitostransfronterizos. Madrid: Traficantes de Sueños.

Segato, R.L. (2004). Territorio, soberanía y crimenes de segundo estado. La escritura en el cuerpo de las mujeres asesinadas en Ciudad Juárez. Recuperado de https://www.forosalud.org.pe/territorio_soberania.pdf

Selek, P. (2014). Devenir homme en rampant. Paris: l'Harmattan.

Tabet, P. (2005). Las manos, los instrumentos, las armas. En O. Curiel y J. Falquet (eds), El patriarcado al desnudo. Tres feministas materialistas. Bogotá: Brecha Lésbica.

Tabet, P. (2004). La grande arnaque. Sexualitédesfemmes et échangeéconomico-sexuel (pp. 57-129). Paris: I'Harmattan. 